\title{
Is photographic posture analysis and trunk control different in hemiparetic and diparetic children with cerebral palsy?
}

\author{
Betul Erbay, Pt, MSc ${ }^{1}$, Nilay Comuk Balci, Pt, PhD2* \\ 'Department of Therapy and Rehabilitation, Bartin Univeristy, Bartin-Turkey \\ ${ }^{2}$ Department of Physiotherapy and Rehabilitation, Faculty of Health Sciences, Ondokuz Mayıs \\ University, Samsun, Turkey
}

Received: 28 December, 2021

Accepted: 06 January, 2022

Published: 07 January, 2022

*Corresponding author: Nilay Comuk Balci, Pt, PhD, Department of Physiotherapy and Rehabilitation, Faculty of Health Sciences, Ondokuz Mayıs University, Samsun, Turkey, E-mail: nilay.comukbalci@omu.edu.tr ORCID: https://orcid.org/0000-0002-3617-6345 Keywords: Photographic posture analysis; Cerebral palsy; Trunk control

Copyright License: (C) 2022 Erbay B, et al. This is an open-access article distributed under the terms of the Creative Commons Attribution License, which permits unrestricted use, distribution, and reproduction in any medium, provided the original author and source are credited.

https://www.peertechzpublications.com

\section{Abstract}

Objective: Photographic posture analysis is a useful, inexpensive, time-efficient, and non-invasive method to assess posture. The primary purpose of this study was to compare PPA and trunk control between children with Diparetic and Hemiparetic Cerebral Palsy (CP).

Methods: Fifty-two children with hemiparetic and diparetic CP whose GMFCS levels I and II were compared with PPA in sitting position and also trunk control was measured with Trunk Control Measurement Scale (TCMS).

Results: There was no scientific difference in craniovertebral angle, sagittal head tilt, sagittal shoulder-C7 angle, thoracic kyphosis angle, coronal head tilt, coronal shoulder angle, coronal pelvic angle in PPA and TCMS between groups ( $p>0.05)$, however, there was a scientific difference in lumbar lordosis angle in PPA between the groups $(p<0.05)$.

Conclusion: Lumbar lordosis is more common in children with hemiparetic CP than diparetic CP. It can be thought that this situation requires children to change their body biomechanics to compensate their affected sides more than the children with diparetic CP. The physicians should take care of the postural alignment of the lumbar and pelvic girdle of hemiparetic CP. We think that muscle strength, muscle shortness, and other lower extremity biomechanics that could increase lordosis should be examined in detail in hemiparetic CP regardless of where the origin of lumbar lordosis (pelvis or lumbar region).

\section{Introduction}

Cerebral Palsy (CP) is a group of non-progressive permanent disorders if the fetal and neonatal brain is affected by various reasons in the prenatal, perinatal, and postnatal period first described by William Little in 1862. As a result, activity limitations affect muscle control, movement, posture, and balance [1]. Damage to the central nervous system in children with $\mathrm{CP}$ affects the motor and sensory system and causes these children to reach normal stages of development lately. As a result of primary brain lesion, abnormal muscle tones, muscle weaknesses, decreased selective control, impaired balance and coordination are observed.

Increased coactivation of antagonist's muscles and impaired reciprocal innervation in selected muscle groups cause poor postural control and postural misalignments in children with $\mathrm{CP}$ [2]. Therefore, children with $\mathrm{CP}$ have developed compensator mechanisms to deal with secondary musculoskeletal system problems associated with poor postural strategies [3-5]. During the rehabilitation process, the therapist aimed to improve postural control of the antigravity torso muscles to achieve a stable sitting position, which is important for maintaining upper extremity functions, eyehand coordination, self-care activities, social interaction, and cognitive skills in children with $\mathrm{CP}[6,7]$.

Current research has shown that postural control and postural misalignment deficiency in the sitting position occurs in children with $\mathrm{CP}$ and is usually measured by a goniometer, 
inclinometer, flexicurve, spinal mouse, and modified head posture spinal curvature tool to evaluate posture in the sitting position [8-13]. Photographic Posture Analysis (PPA) is the most commonly used method for noninvasive measurement of postural measures that evaluate the position of the spine in the sitting posture using anatomical reference points and is a digital, valid, and reliable measurement. PPA is calculated by specially designed software that measures postural evaluation by measuring linear distances and angles (created between body markers and lines produced through horizontal or vertical lines) in digital photos using software specifically designed for this purpose [14-17]. Based on these advantages, PPA is a convenient and useful method for evaluating sitting posture $[14,15,18,19]$. Many studies investigated the reliability and validity of PPA in adolescents $[14,20,21]$. Lee, et al. (20) demonstrated the test-retest reliability of PPA was good to high for sitting, standing, walking, and running conditions to evaluate the head-positions in young adults. Also, they indicated that comfort sitting position had high ICC values and in contrast to literature tragus $\mathrm{C} 7$ was a more reliable marker than craniovertebral angle for PPA. Similarly, Niekerk, et al. [14] showed fair to high reliability of the photographic measurement of high school students in sitting posture. In addition, this previous study was demonstrated a moderate to good correlation when compared by radiography. In the light of these findings, the PPA can be a promising method to estimate the posture in children and adolescents $[14,20]$. On reviewing previous studies, it can be seen that, although many studies have been conducted on children and adolescents with typical development, there are very few studies in $\mathrm{CP}$ that investigated the PPA [22] and no study compared PPA between hemiparetic and diparetic CP. Therefore, the main objective of this study was to compare PPA in sitting position and trunk control between children with diparetic and hemiparetic CP.

\section{Materials and methods}

The design of the present study was a cross-sectional study. The University Ethics Committee approved the study (KA19/126 19/52) and all of the participants and their parents were informed about the objectives and procedures of the study, and an informed written consent form was obtained.

\section{Participants}

Fifty-two children with hemiparetic and diparetic CP were referred by pediatric neurologists were included in the study. The inclusion criteria were (1) a diagnosis of CP (hemiparetic or diparetic), (2) age 5-12 years, (3) motor function classified as level of "I, II" according to Gross Motor Function Classification System (GMFCS), (4) ability to sit without assistive devices, (5) able to understand all verbal commands. The exclusion criteria were (1), applied spinal surgery, botulinum toxin (BoNT), and surgical treatment in the last 6 months, (2) another neurodevelopmental or congenital disease other than CP.

\section{Clinical measurements}

Mobility was classified using the Gross Motor Function Classification System (GMFCS) [23].

\section{Postural evaluation}

The postural evaluation was done using the photographic method. All measurements were made by a researcher experienced in postural analysis evaluation. Nikon digital camera (Nikon Corp., Japan), model D5100, with a serial number of 8359844; a national geographic tripod with a double spirit level, 15- mm polystyrene reflective balls, double-sided adhesive tape. The camera was placed on a $115 \mathrm{~cm}$ high tripod, $1.5 \mathrm{~m}$ away from the participants. Spirit levels have been adjusted so that the tripod is completely flat on the ground. The tripod was taped to the floor to maintain the same distance between the camera and the participants. Three photographs of each child whose feet were on the ground, in a free-sitting position, one from the front and two from the sides were taken by the researchers. In PPA we used external bony landmarks to estimate spinal posture, on the understanding that what is being measured externally reflects the shape of structures underlying the spine. Before taking pictures affixing of small polystyrene reflective balls to the skin at indicated anatomical points of the participants for more accurate and easier angular calculations. These points are cantus, tragus, acromion, the midpoint of humerus, the spinal process of cervical 7 and torocal 12, Spina iliaca anterior superior, trochanter major. The photographic analysis was subsequently performed using a software program that was made by the faculty members of the biomechanics program for postural analysis which determined the coordinates of the anatomical points on the photographs. The zoom was standardized at $200 \%$, and the angles were measured in degrees between 3 points [14,17,24]. The angles calculated for the PPA were:

1. Craniovertebral angle: Where a line drawn from the tragus of the ear to the $\mathrm{C} 7$ vertebra intersects a horizontal line, the Craniovertebral angle is formed. It is used to measure the value of forward head posture, and the greater the value of this angle, the more forward the head is positioned on the neck (Figure 1) [24].

2. Sagittal head tilt: It is a measure of the posture of the upper cervical spine. This angle, which is formed between a line from the canthus of the eye and the tragus of the ear and the horizontal, is a measure of the posture of the upper cervical spine. The smaller the value of this angle, the higher forward head posture (Figure 2) [24].

3. Sagittal shoulder-C7 angle: Where a horizontal line passing through the lateral shoulder meets the line drawn from $\mathrm{C} 7$ to the lateral shoulder, the point of intersection forms the sagittal shoulder-C7 angle. It indicates the degree of protraction of the shoulders. The value of this angle decreases as the degree of protection increases (Figure 3) [24].

4. Thoracic kyphosis angle: The point where the lines produced perpendicular to the skin surface from the T12 and C7 spinal processes intersect each other forms the thoracic flexion angle. The smaller the angle, the less the degree of kyphosis (Figure 4) [24].

Citation: Erbay B, Balci NC (2022) Is photographic posture analysis and trunk control different in hemiparetic and diparetic children with cerebral palsy? J Nov 
5. Lumbar lordosis angle: The angle between the lines drawn from the Spina iliaca anterior superior to the T12 spinal process and to the trochanter major forms the lumbal lordosis angle (Figure 5) [25].

6. Coronal head tilt: It is a measure of the lateral flexion of the head formed between the line drawn from the tragus and the horizontal line. Its normal value should be 180 degrees (Figure 6-A) [24].

7. Coronal shoulder angle: It is defined as the angle formed between the line connecting the coracoid protrusions and the horizontal line. It is used to determine whether the left and right shoulders are straight. Its normal value should be 180 degrees (Figure 6-B) [24].

8. Coronal pelvic angle: The angle formed between the line connecting Spina iliaca anterior superiors and the horizontal line. Used to assess pelvic deviation (Figure 6-C) [18].

\section{Evaluation of trunk control}

Trunk control was evaluated with Trunk Control Measurement Scale (TCMS). TCMS is a scale that measures
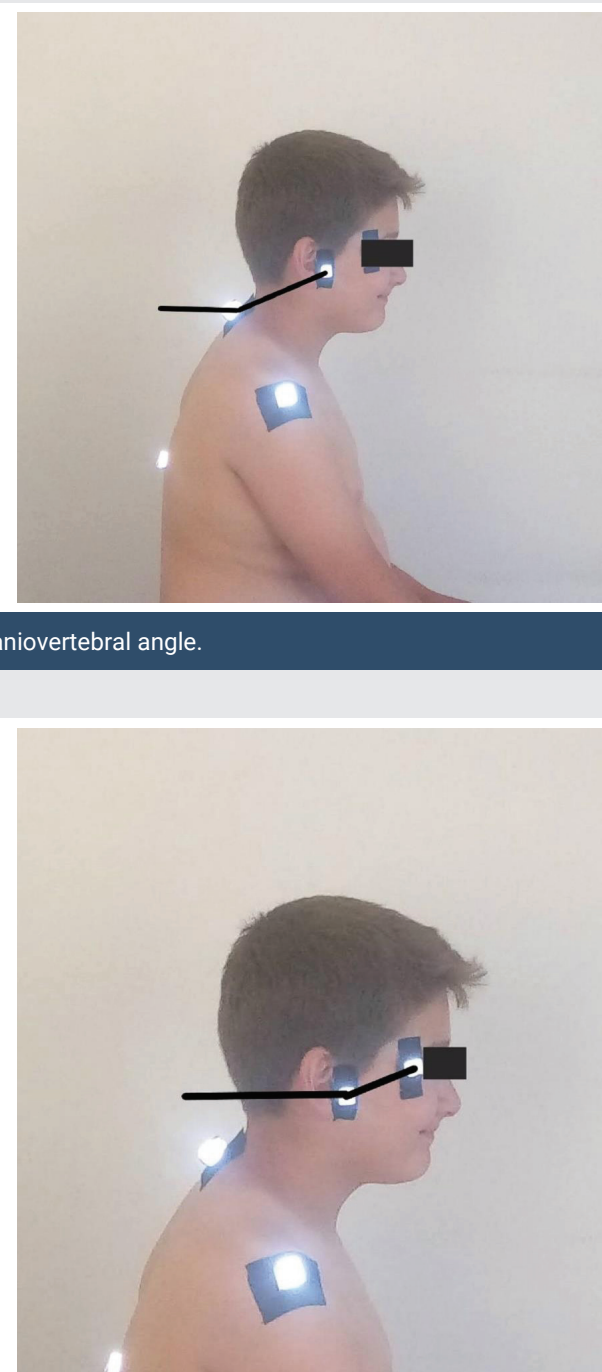
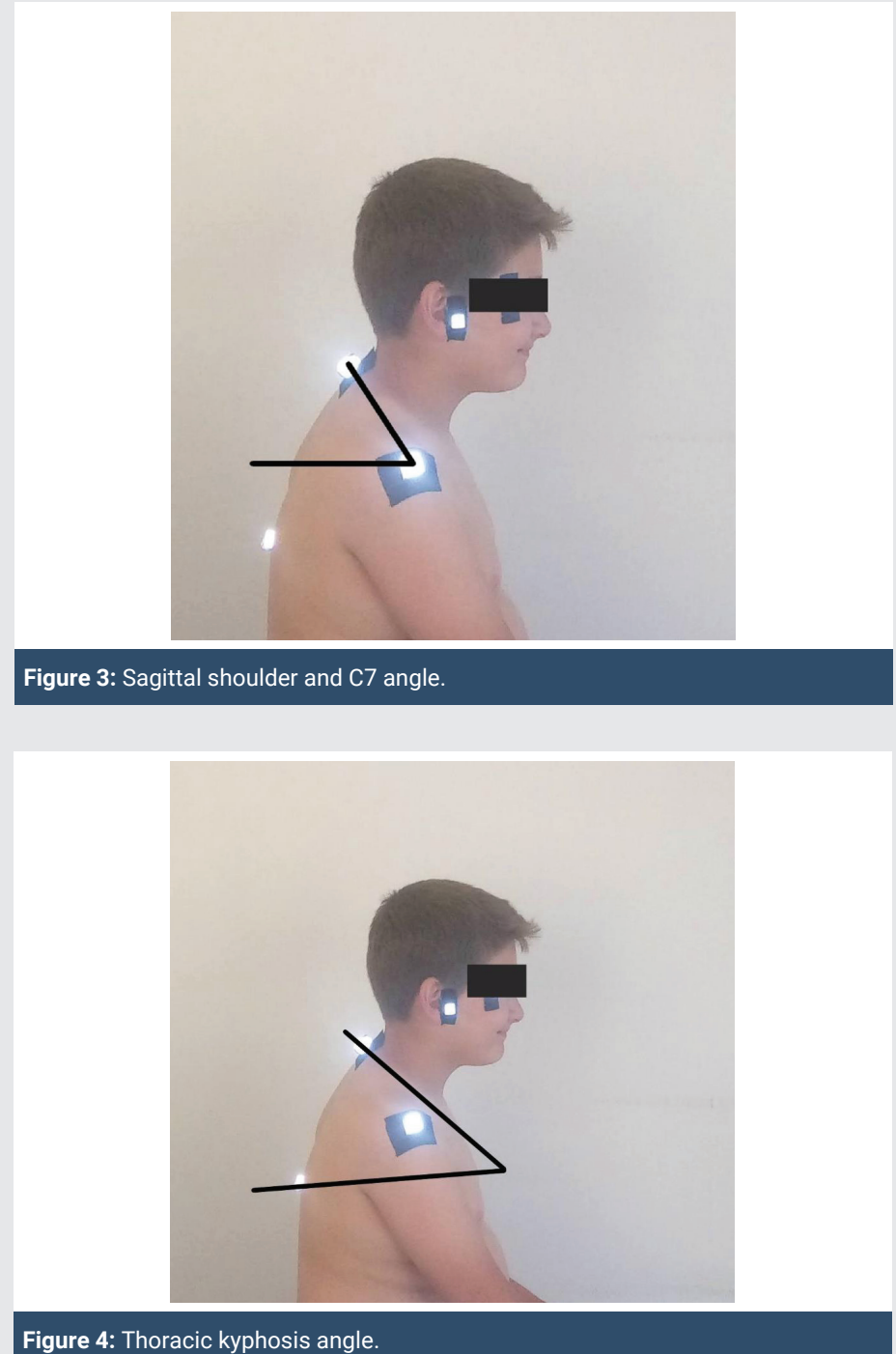

Figure 4: Thoracic kyphosis angle.

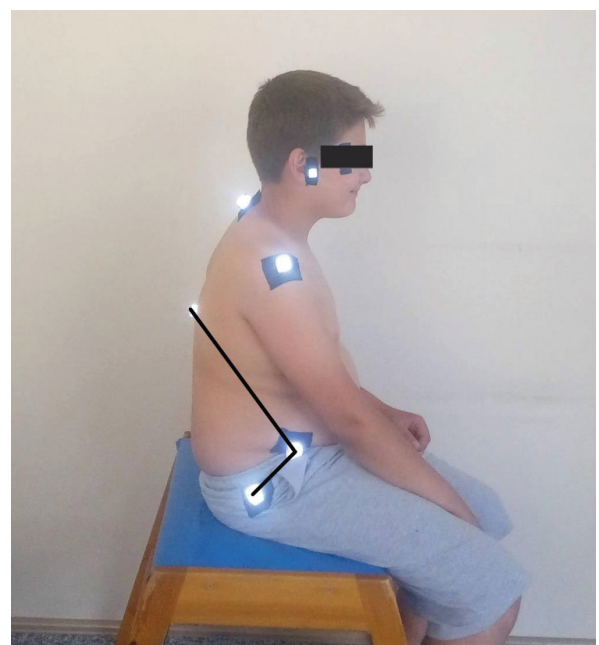

Figure 5: Lumbal lordosis angle.

the static and dynamic sitting balance in children with CP. It consists of 15 items in total, 1-5 items measure Static Sitting Balance, 6-15 items measure dynamic sitting balance. Static sitting balance assesses the ability of children to maintain the trunk posture as they move their upper and lower limbs in the 


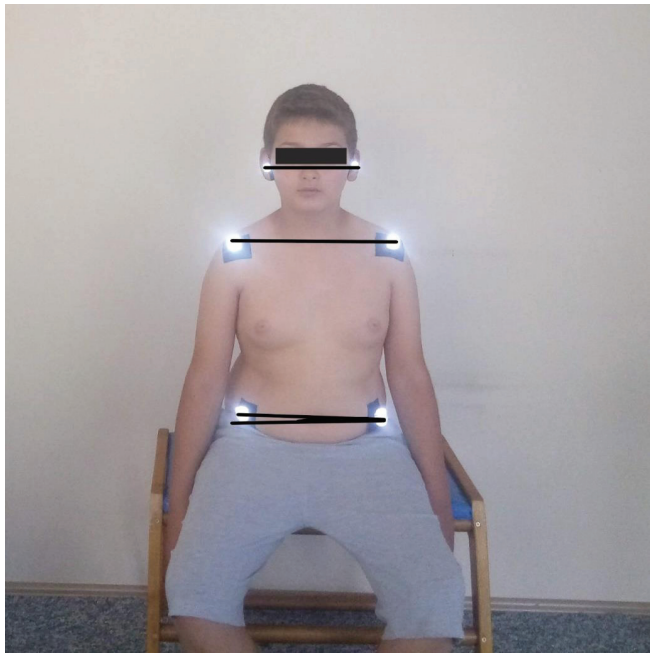

Figure 6: A) Coronal head tilt B) Coronal shoulder angle C) Coronal pelvis angle.

sitting posture. Dynamic sitting balance is divided into two sub-scales; selective motion control scale and dynamic reach scale. The maximum score that can be obtained from the test is 58. Higher scores perform better [26]. TCMS was measured after the PPA.

\section{Statistical analysis}

The results of tests were expressed as the number of observations $(\mathrm{n})$, mean \pm standard deviation. The results of the homogeneity (Levene's test) and normality tests (Shapiro Wilk) were used to decide which statistical methods to apply in the comparison of the study groups. Normally distributed and with homogeneous variances groups were compared to two groups by Student's t-test. According to those tests results, parametric test assumptions were not available for some variables, so the comparisons of two independent groups were performed by the Mann-Whitney U test. Categorical data were analyzed with Fischer's Exact Test and Chi-square test. Expected to be less than $20 \%$ of cells in cases for inclusion in the analysis of those cells "Monte Carlo Simulation Method" and the values were determined. All statistical analyses were performed with the SPSS software (IBM Corp. Released 2017. IBM SPSS Statistics for Windows, Version 25.0 Armonk, NY: IBM Corp.). p-value of $<.05$ and $<.01$ was considered statistically significant. Before the study, trunk control was determined as a result of the power analysis and the required sample width was at least 50 individuals in total. The expected value of the power of the test was determined to be approximately $82.4 \%$.

\section{Results}

Table 1 provides demographic characteristics of children. In our study, the groups were similar in terms of age, gender, GMFCS levels and parental characteristics ( $p>0.05$ ), but there was a significant difference between body weight results $(\mathrm{p}<0.05)$. Table 2 shows PPA and TCMS results between hemiparetic and diparetic CP. All parameters were similar between the groups ( $p>0.05$ ) whereas there was a significant difference between the groups in Lumbar lordosis angle $(\mathrm{p}<0.05)$.

\section{Discussion}

Photographic posture analysis is a useful, inexpensive, time-efficient, and non-invasive method to assess posture. The primary purpose of this study was to compare PPA and trunk control between children with diparetic and hemiparetic $\mathrm{CP}$. We found no scientific difference in craniovertebral angle, sagittal head tilt, sagittal shoulder-C7 angle, thoracic kyphosis angle, coronal head tilt, coronal shoulder angle, coronal pelvic angle in PPA and in TCMS between groups p>0.05, whereas found a scientific difference in lumbar lordosis angle in PPA between the groups $\mathrm{p}<0.05$.

It was difficult to compare the present results with those in the literature because most of these studies involved healthy children and adolescents. Domagalska-Szopa, et al. [26] made a study showing standing sagittal postural alignment in bilateral $\mathrm{CP}$ and found three types of posture: 1) lordotic postural pattern corresponding to forward-leaning posture; 2) a swayback postural pattern corresponding to backward-leaning posture, and 3) a balanced postural pattern corresponding to balanced posture but did not explain how these postures emerged. Our study is different from this study because we used a sitting

\begin{tabular}{|c|c|c|c|c|}
\hline & & $\begin{array}{l}\text { Hemiplegia } \\
\begin{array}{c}n=26 \\
\bar{x} \pm S D\end{array}\end{array}$ & $\begin{array}{c}\text { Diplegia } \\
\begin{array}{c}n=26 \\
\bar{x} \pm S D\end{array}\end{array}$ & p \\
\hline \multicolumn{2}{|c|}{ Age (years) } & $8.80 \pm 2.57$ & $10.11 \pm 2.06$ & 0.061 \\
\hline \multicolumn{2}{|c|}{ Weight (kg) } & $30.61 \pm 12.50$ & $37.88 \pm 10.88$ & $0.033^{*}$ \\
\hline \multicolumn{2}{|c|}{ GMFCS Level } & $1.50 \pm 0.50$ & $1.50 \pm 0.50$ & 1.000 \\
\hline \multicolumn{2}{|c|}{ Gestational Age (weeks) } & $37.19 \pm 3.34$ & $35.50 \pm 4.25$ & 0.117 \\
\hline \multicolumn{2}{|c|}{ Maternal Age (years) } & $35.76 \pm 4.90$ & $36.88 \pm 2.98$ & 0.174 \\
\hline \multicolumn{2}{|c|}{ Paternal Age (years) } & $38.96 \pm 4.92$ & $39.84 \pm 3.23$ & 0.321 \\
\hline & & $\%(n)$ & $\%(n)$ & \\
\hline \multirow{2}{*}{ Gender } & Girls & $50.0(13)$ & $50.0(13)$ & 1.000 \\
\hline & Boys & $50.0(13)$ & $50.0(13)$ & 1.000 \\
\hline \multirow{2}{*}{ Effected side } & Right & $57.7(15)$ & \multirow{2}{*}{ - } & - \\
\hline & Left & $42.3(11)$ & & - \\
\hline
\end{tabular}

CP: Cerebral Palsy; GMFCS: Gross Motor Function Classification System * $\mathrm{p}<0.05$

Table 2: Comparing PPA and TCMS results between hemiparetic and diparetic CP.

\begin{tabular}{|c|c|c|c|}
\hline & $\begin{array}{c}\text { Hemiplegia } \\
\begin{array}{c}n=26 \\
\bar{x} \pm S D\left({ }^{\circ}\right)\end{array}\end{array}$ & $\begin{array}{c}\text { Diplegia } \\
\mathbf{n}=26 \\
\bar{x} \pm S D\left({ }^{\circ}\right)\end{array}$ & $\mathbf{p}$ \\
\hline Craniovertebral angle & $148.30 \pm 11.95$ & $144.80 \pm 11.58$ & 0.385 \\
\hline Sagittal head tilt & $156.54 \pm 7.15$ & $157.51 \pm 9.71$ & 0.667 \\
\hline Sagittal shoulder and C7 angle & $56.41 \pm 8.79$ & $57.95 \pm 9.49$ & 0.546 \\
\hline Thoracic kyphosis angle & $53.54 \pm 9.40$ & $52.23 \pm 9.57$ & 0.826 \\
\hline Lumbar lordosis angle & $101.68 \pm 13.13$ & $108.98 \pm 13.88$ & $0.046^{*}$ \\
\hline Coronal head tilt & $1.91 \pm 1.87$ & $2.68 \pm 2.43$ & 0.252 \\
\hline Coronal shoulder angle & $2.62 \pm 2.81$ & $1.76 \pm 1.50$ & 0.516 \\
\hline Coronal pelvis angle & $2.40 \pm 1.55$ & $2.09 \pm 1.73$ & 0.231 \\
\hline TCMS Static sitting & $18.92 \pm 1.71$ & $18.53 \pm 1.90$ & 0.402 \\
\hline TCMS Selective movement & $14.92 \pm 3.49$ & $14.38 \pm 3.34$ & 0.762 \\
\hline TCMS Dynamic reach & $9.26 \pm 1.56$ & $9.34 \pm 2.46$ & 0.422 \\
\hline TCMS Total score & $43.11 \pm 5.03$ & $41.84 \pm 5.36$ & 0.533 \\
\hline
\end{tabular}

TCMS: Trunk Control Measurement Scale; CP: Cerebral Palsy; ${ }^{*} \mathrm{p}<0.05{ }^{* \star} \mathrm{p}<0.01$

Citation: Erbay B, Balci NC (2022) Is photographic posture analysis and trunk control different in hemiparetic and diparetic children with cerebral palsy? J Nov Physiother Phys Rehabil 9(1): 001-007. DOI: https://dx.doi.org/10.17352/2455-5487.000094 
position to eliminate the postural sway of the body and we wanted it to be a clinically convenient measurement. In this study, while no difference was observed between the groups in the coronal plane in hemiparetic and diparetic $\mathrm{CP}$, it was revealed that there was only a difference between the lumbar lordosis angle in the sagittal plane. The lumbar lordosis angle is greater in diparetic children than in hemiparetic children. The smaller the angle, the greater the hyperlordosis. The greater the angle, the greater the rectification [27]. Accordingly, it can be said that lumbar lordosis is more common in hemiparetic children. It can be thought that this situation requires children to change their body biomechanics to compensate their affected sides more than the children with diparetic CP. While there is symmetrical involvement in diparetic children, there is asymmetrical involvement in hemiparetic children. We think that it is difficult to compensate for the asymmetry and try to compensate the body biomechanics accordingly. According to Bendix, et al. [28] these changes occurred because of trunk displacements to reduce the anterior body tilt perceptions and the tendency to hyperextend the hip due to the posterior pelvic tilt. The pelvis is considered a key structure of body alignment, and any changes in its neutral position will cause compensatory movements in various regions, with the lumbar spine being one of the most affected segments. Lumbar spine posture is directly related to pelvic postures, and therefore, the literature describes the changes in lumbar lordosis in conjunction with changes in the pelvic segments. Maybe lower body compensations moved the center of gravity anteriorly, and therefore, there was a need to regain balance; hence, they ended up tilting their pelvis posteriorly, just as what happened with lumbar rectification. However, as previously described, it is worthy to note that pelvic positioning is related to lumbar lordosis because pelvic movements are closely related to the biomechanics of the lumbar spine. Lapierre [29]. considered that balance seeks stability and should initially be organized according to the stability of the pelvis over the hips. Any inclinations of the pelvis would involve simultaneous movements of the lumbar spine and the hip joints. If the lumbar paraspinal muscles predominate over the retroversion muscles, the pelvis will move toward anteversion, aided by the hip flexor muscles. We think that muscle strength, muscle shortness, and other lower extremity biomechanics that could increase lordosis should be examined in detail in hemiparetic children regardless of where the origin of lumbar lordosis (pelvis or lumbar region).

Masaki, et al. [30] revealed that lumbar multifidus muscle thickness and body weight were significant and independent factors of the lumbar lordosis angle in the sitting position. In our study, the bodyweight of children with diparetic CP was significantly higher. We think that this situation should also be taken into account. Stokes and Abery [31], using tracings from photographs, found a positive correlation between spine flexion (kyphosis) and hamstring tightness in normal adult subjects, but this was not statistically significant. Gajdosik, et al. [32], using similar techniques, found a decrease in the flexion range of motion of the spine in patients with tight hamstrings. Both studies demonstrate an association between tight hamstrings and altered sagittal alignment of the spine, although neither study measured the lumbar curve radiographically. McCarthy, et al. showed that the lumbar lordosis decreases as the popliteal angle increases; therefore, children with tight hamstrings sit with a hypolordotic or even kyphotic lumbar spine [33].

According to Harada, et al. [34], the average angle of lumbar lordosis in spastic patients in the standing position was greater than in normal subjects and increased with age in radiography. The patients had a decreased sacrofemoral angle which caused an increase in Ferguson's angle and explained the increased angle of lumbar lordosis. Three radiography studies have explored and described the spinopelvic sagittal alignment of walking $\mathrm{CP}$ patients, who often present retraction of hip flexors (right anterior, iliopsoas) [35-37]. Pelvic incidence was found to be similar to that of healthy controls, indicating that the shape of the pelvis was not affected by the disease [35]. However, the pelvis was anteverted (low pelvic tilt) and the sacrum was more horizontal (high sacral slope). Lumbar lordosis was reduced compared with controls and not correlated with pelvic incidence. As a result, ambulant CP patients usually had an anterior imbalance in standing position. Furthermore, hip flexion contractures and abnormal pelvic orientation may play associative and causative roles in the onset and evolution of sagittal abnormalities secondary to the abnormal forces exerted between the lumbar spine and pelvis [35]. Generally, lumbar hyperlordosis is responsible for pelvic anteversion, and the anterior flexion of the pelvic ring in $\mathrm{CP}$ and lumbar hyperlordosis in $\mathrm{CP}$ is assumed to be related to combinations of proximal (spinal) and distal (pelvic) causes [38-40]. Therefore, we believe that analyses of pelvic position and lumbar-pelvic sagittal alignment should be a fundamental part of the patient assessment and that a comprehensive analysis of the spinopelvic parameters affected by sagittal deformities is needed.

Trunk control has a crucial role to achieve postural control mechanisms. Especially, trunk control provides stabilization and base of support for daily living activities by activating multifidus and transversus abdominus. Panibatla, et al. [41] investigated the relationship between trunk control and balance in children with $\mathrm{CP}$. They found a very strong correlation between the static component of trunk control and the dynamic component of balance. Trunk control is one of the basic components for protecting stable posture during voluntary activities in CP [42]. We thought that the development of trunk postural balance and motor skills may have a more positive effect on posture regulation and stability control. To maintain balance with optimal efferent muscle activity, afferent sensory information must be processed from a neurospatial perspective and there must be an adequate neural control system [43,44]. Only neutral back spine posture (natural and balanced lumbar, thoracal and cervical curves) and well-balanced pelvis provide opportunities to keep the line of gravity with optimal energy $[45,46]$. Since the GMFCS levels were 1 and 2 in the population in our study, it is thought that the results related to trunk control were similar between the groups. However, considering that it may be related to photographic posture analysis, we performed trunk control measurement in our study. 
In conclusion, valid and reliable measurement tools which are easily accessible, cheap, non-invasive, and have no side effects are crucial for researchers and clinicians. Therefore, researchers try to find alternative methods to analyze posture in current literature instead of the radiography that is the gold standard for assessing sitting posture [14]. The limitations of this study are that the pelvic horizontal alignment angle was not measured in the sagittal plane and no standing PPA was performed. In our study, it was thought that the sitting measurement would give more accurate results by reducing the postural sway. Future studies could investigate the PPA in CP with different GMFCS levels and different types of $\mathrm{CP}$ with larger sample size. We think that muscle strength, muscle shortness, and other lower extremity biomechanics that could increase lordosis should be examined in detail. Also, studies evaluating balance and advanced gross motor skills can be carried out with PPA. The realization of such studies will guide clinical rehabilitation professionals. Measuring posture repeatedly and providing preventive and appropriate intervention guidance for rehabilitation professionals will be clinically important to learn about the motor functions of the children.

Clinical trial registration numbers and date of registration: This trial was registered on ClinicalTrials.gov (NCT04409730) Registered 27 May 2020

Conflict of Interest: The authors declare no conflict of interest.

Funding Statement: This research received no specific grant from any funding agency in the public, commercial or not-for-profit sectors.

\section{References}

1. Rosenbaum P, Paneth N, Leviton A, Goldstein M, Bax M, et al. (2007) A report: the definition and classification of cerebral palsy April 2006. Dev Med Child Neurol Suppl 109: 8-14. Link: https://bit.ly/3zG08Lx

2. Colver A, Fairhurst C, Pharoah PO (2014) Cerebral palsy. Lancet 383: 12401249. Link: https://bit.ly/3fOH9CO

3. Domagalska-Szopa M, Szopa A (2017) Postural orientation and standing postural alignment in ambulant children with bilateral cerebral palsy. Clin Biomech (Bristol, Avon) 49: 22-27. Link: https://bit.ly/3t5JEer

4. Chung J, Evans J, Lee C, Rabbani Y, Roxborough L, et al. (2008) Effectiveness of adaptive seating on sitting posture and postural control in children with cerebral palsy. Pediatr Phys Ther 20: 303-317. Link: https://bit.ly/3JNbTEA

5. Brogren E, Hadders-Algra M, Forssberg H (1998) Postural control in sitting children with cerebral palsy. Neurosci Biobehav Rev 22: 591-596. Link: https://bit.ly/3qu8w6i

6. de Graaf-Peters VB, Blauw-Hospers $\mathrm{CH}$, Dirks T, Bakker H, Bos AF, et al. (2007) Development of postural control in typically developing children and children with cerebral palsy: possibilities for intervention?. Neurosci Biobehav Rev 31 1191-1200. Link: https://bit.ly/3JQSkLN

7. Bañas BB, Gorgon EJ (2014) Clinimetric properties of sitting balance measures for children with cerebral palsy: a systematic review. Phys Occup Ther Pediatr 34: 313-334. Link: https://bit.ly/3t2ZB4W

8. Pringle RK (2003) Intra-instrument reliability of 4 goniometers. J Chiropr Med 2: 91-95. Link: https://bit.ly/33cABNJ

9. Youdas JW, Carey JR, Garrett TR (1991) Reliability of measurements of cervical spine range of motion--comparison of three methods. Phys Ther 71 98-106. Link: https://bit.ly/33cRjMU

10. Tousignant M, Boucher N, Bourbonnais J, Gravelle T, Quesnel M, et al. (2001) Intratester and intertester reliability of the Cybex electronic digital inclinometer (EDI-320) for measurement of active neck flexion and extension in healthy subjects. Man Ther 6: 235-241. Link: https://bit.ly/3300FKu

11. Harrison DE, Haas JW, Cailliet R, Harrison DD, Holland B, et al. (2005) Concurrent validity of flexicurve instrument measurements: sagittal skin contour of the cervical spine compared with lateral cervical radiographic measurements. J Manipulative Physiol Ther 28: 597-603. Link: https://bit.ly/3n366RG

12. Subbarayalu AV (2016) Measurement of craniovertebral angle by the Modified Head Posture Spinal Curvature Instrument: A reliability and validity study. Physiother Theory Pract 32: 144-152. Link: https://bit.ly/3HLmZlf

13. Livanelioglu A, Kaya F, Nabiyev V, Demirkiran G, Firat T (2016) The validity and reliability of "Spinal Mouse" assessment of spinal curvatures in the frontal plane in pediatric adolescent idiopathic thoraco-lumbar curves. Eur Spine $\mathrm{J} 25$ 476-482. Link: https://bit.ly/3JSgfum

14. Niekerk SM, Louw Q, Vaughan C, Grimmer-Somers K, Schreve K (2008) Photographic measurement of upper-body sitting posture of high schoo students: a reliability and validity study. BMC Musculoskelet Disord 9: 113 Link: https://bit.ly/3zwLczo

15. Pausić J, Pedisić Z, Dizdar D (2010) Reliability of a photographic method for assessing standing posture of elementary school students. J Manipulative Physiol Ther 33: 425-431. Link: https://bit.ly/3sZte7o

16. Weber P, Corrêa ECR, Milanesi JM, Soares JC, Trevisa ME (2012) Craniocervical posture: cephalometric and biophotogrammetric analysis. Braz J Oral 11: 416 421. Link: https://bit.ly/320N9ve

17. Ruivo RM, Pezarat-Correia P, Carita Al (2014) Cervical and shoulder postural assessment of adolescents between 15 and 17 years old and association with upper quadrant pain. Braz J Phys Ther 18: 364-371. Link: https://bit.ly/3npvXDF

18. Hazar Z, Karabicak GO, Tiftikci U (2015) Reliability of photographic posture analysis of adolescents. J Phys Ther Sci 27: 3123-3126. Link: https://bit.ly/3JLNSOd

19. Fortin C, Feldman DE, Cheriet F, Labelle H (2011) Clinical methods for quantifying body segment posture: a literature review. Disabil Rehabil 33: 367 383. Link: https://bit.ly/3t3A2Rn

20. Lee $\mathrm{CH}$, Lee S, Shin G (2017) Reliability of forward head posture evaluation while sitting, standing, walking and running. Hum Mov Sci 55: 81-86. Link: https://bit.ly/3fOvPFW

21. Cuccia AM, Carola C (2009) The measurement of craniocervical posture: a simple method to evaluate head position. Int J Pediatr Otorhinolaryngol 73 1732-1736. Link: https://bit.ly/3n3HkBO

22. Domagalska-Szopa M, Szopa A (2017) Postural orientation and standing postural alignment in ambulant children with bilateral cerebral palsy. Clin Biomech (Bristol, Avon) 49: 22-27. Link: https://bit.ly/3t3AgYJ

23. Palisano RJ, Rosenbaum P, Bartlett D, Livingston MH (2008) Content validity of the expanded and revised Gross Motor Function Classification System. Dev Med Child Neurol 50: 744-750. Link: https://bit.ly/34nwWgJ

24. Singla D, Veqar Z, Hussain ME (2017) Photogrammetric Assessment of Uppe Body Posture Using Postural Angles: A Literature Review. J Chiropr Med 16 131-138. Link: https://bit.ly/3qSJjsY

25. Porto AB, Okazaki VHA (2017) Procedures of assessment on the quantification of thoracic kyphosis and lumbar lordosis by radiography and photogrammetry: A literature review. J Bodyw Mov Ther 21: 986-994. Link: https://bit.ly/3n5CiUp

Citation: Erbay B, Balci NC (2022) Is photographic posture analysis and trunk control different in hemiparetic and diparetic children with cerebral palsy? J Nov Physiother Phys Rehabil 9(1): 001-007. DOI: https://dx.doi.org/10.17352/2455-5487.000094 
26. Heyrman L, Molenaers G, Desloovere K, Verheyden G, De Cat J, et al. (2011) A clinical tool to measure trunk control in children with cerebral palsy: the Trunk Control Measurement Scale. Res Dev Disabil 32: 2624-2635. Link: https://bit.ly/3JQEYPk

27. de Oliveira Pezzan PA, João SM, Ribeiro AP, Manfio EF (2011) Postural assessment of lumbar lordosis and pelvic alignment angles in adolescent users and nonusers of high-heeled shoes. J Manipulative Physiol Ther 34: 614-621. Link: https://bit.ly/3eVhcDT

28. Bendix T, Sorenson SS, Klausen K (1984) Lumbar curve, trunk muscles and line of gravity with different heel heights. Spine (Phila Pa 1976) 9: 223-227. Link: https://bit.ly/3JLWXqd

29. Lapierre A (1982) A reeducação física. Editora Manole.

30. Masaki M, Ogawa Y, Inagaki Y, Sato Y, Yokota M, et al. (2021) Association of sagittal spinal alignment in the sitting position with the trunk and lower extremity muscle masses in children and adults with cerebral palsy: A pilot study. Clin Biomech (Bristol, Avon) 90: 105491. Link: https://bit.ly/3zAACYf

31. Stokes IAF, Abery JM (1980) Influence of the hamstring muscles on lumbar spine curvature in sitting. Spine (Phila Pa 1976) 5: 525-528. Link: https://bit.ly/3F4Tm2S

32. Gajdosik RL, Albert CR, Mitman JJ (1994) Influence of hamstring length on the standing position and flexion range of motion of the pelvic angle, lumbar angle and thoracic angle. J Orthop Sports Phys Ther 20: 213-219. Link: https://bit.ly/3n2Dyrk

33. McCarthy JJ, Betz RR (2000) The relationship between tight hamstrings and lumbar hypolordosis in children with cerebral palsy. Spine (Phila Pa 1976) 25 : 211-213. Link: https://bit.ly/3qYIMXk

34. Harada T, Ebara S, Anwar MM, Kajiura I, Oshita S, et al. (1993) The lumbar spine in spastic diplegia. A radiographic study. J Bone Joint Surg $\mathrm{Br} 75$ : 534 537. Link: https://bit.ly/3eWE31V

35. Suh SW, Suh DH, Kim JW, Park JH, Hong JY (2013) Analysis of sagittal spinopelvic parameters in cerebral palsy. Spine J 13: 882-888. Link: https://bit.ly/3t6CeaO

36. Deceuninck J, Bernard JC, Combey A, Leroy-Coudeville S, Morel E, et al.
(2013) Sagittal X-ray parameters in walking or ambulating children with cerebral palsy. Ann Phys Rehabil Med 56: 123-133. Link: https://bit.ly/3qSJlvu

37. Bernard JC, Deceuninck J, Leroy-Coudeville S, Loustalet E, Morel E et al. (2014) Motor function levels and pelvic parameters in walking or ambulating children with cerebral palsy. Ann Phys Rehabil Med 57: 409-421. Link: https://bit.ly/3HLnq5I

38. Sakai T, Yamada H, Nakamura T, Nanamori K, Kawasaki Y, et al. (2006) Lumbar spinal disorders in patients with athetoid cerebral palsy: a clinical and biomechanical study. Spine 31: E66- E70. Link: https://bit.ly/34nxcwd

39. Vialle R, Khouri N, Guillaumat M (2006) Lumbar hyperlodosis in cerebral palsy: anatomic analysis and surgical strategy for correction. Childs Nerv Syst 22 704-709. Link: https://bit.ly/3HF60al

40. Sink EL, Newton PO, Mubarak SJ, Wenger DR (2003) Maintenance of sagittal plane alignment after surgical correction of spinal deformity in patients with cerebral palsy. Spine 28: 1396-1403. Link: https://bit.ly/3sZtwv0

41. Panibatla S, Kumar V, Narayan A (2017) Relationship between Trunk Contro and Balance in Children with Spastic Cerebral Palsy: A Cross-Sectional Study. J Clin Diagn Res 11: YC05-YC08. Link: https://bit.ly/3q12e5m

42. Rocha-de-Lossada C, Prieto-Godoy M, Sánchez-González JM, Romano V, Borroni D, et al. (2021) Tomographic and aberrometric assessment of firsttime diagnosed paediatric keratoconus based on age ranges: a multicentre study. Acta Ophthalmol 99: e929-e936. Link: https://bit.ly/3t5ii8n

43. Sousa AS, Silva A, Tavares JM (2012) Biomechanical and neurophysiological mechanisms related to postural control and efficiency of movement: a review. Somatosens Mot Res 29: 131-143. Link: https://bit.ly/3JOvF2p

44. Latash ML, Levin MF, Scholz JP, Schöner G (2010) Motor control theories and their applications. Medicina (Kaunas, Lithuania) 46: 382-392. Link: https://bit.ly/3n4DXJU

45. Colver A, Fairhurst C, Pharoah PO (2014) Cerebral palsy. Lancet 383: 12401249. Link: https://bit.ly/3FfLb4d

46. Weon JH, Oh JS, Cynn HS, Kim YW, Kwon OY, et al. (2010) Influence of forward head posture on scapular upward rotators during isometric shoulder flexion. $J$ Bodyw Mov Ther 14: 367-374. Link: https://bit.ly/3G6j74f

\section{Discover a bigger Impact and Visibility of your article publication with} Peertechz Publications

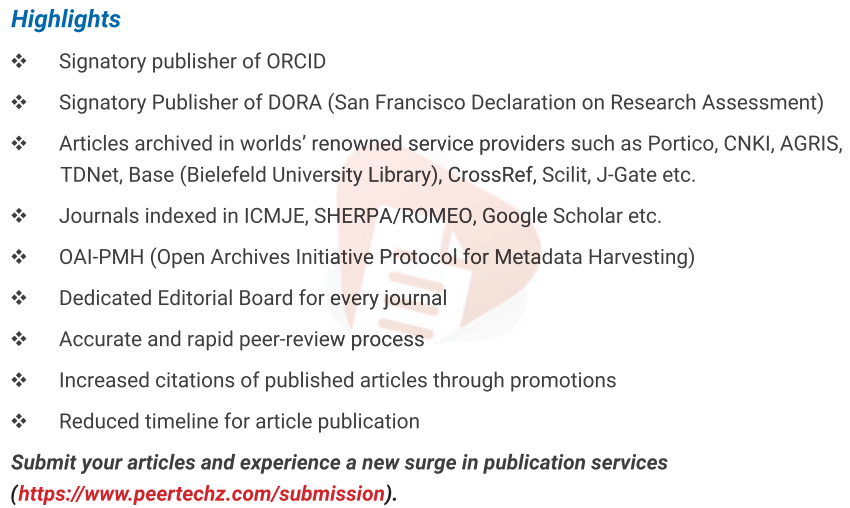

Citation: Erbay B, Balci NC (2022) Is photographic posture analysis and trunk control different in hemiparetic and diparetic children with cerebral palsy? J Nov Physiother Phys Rehabil 9(1): 001-007. DOI: https://dx.doi.org/10.17352/2455-5487.000094 